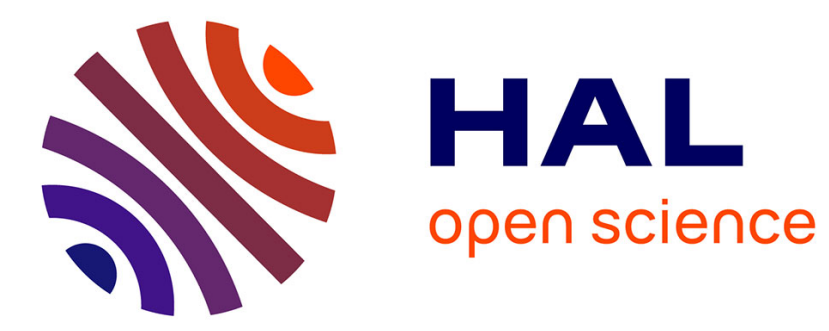

\title{
High temperature spin-driven multiferroicity in ludwigite chromocuprate $\mathrm{Cu} 2 \mathrm{CrBO} 5$
}

Françoise Damay, Jonas Sottmann, François Fauth, Emmanuelle Suard, Antoine Maignan, Christine Martin

\section{- To cite this version:}

Françoise Damay, Jonas Sottmann, François Fauth, Emmanuelle Suard, Antoine Maignan, et al.. High temperature spin-driven multiferroicity in ludwigite chromocuprate $\mathrm{Cu} 2 \mathrm{CrBO} 5$. Applied Physics Letters, 2021, 118 (19), pp.192903. 10.1063/5.0049174 . hal-03298438

\section{HAL Id: hal-03298438 \\ https://hal.science/hal-03298438}

Submitted on 23 Jul 2021

HAL is a multi-disciplinary open access archive for the deposit and dissemination of scientific research documents, whether they are published or not. The documents may come from teaching and research institutions in France or abroad, or from public or private research centers.
L'archive ouverte pluridisciplinaire HAL, est destinée au dépôt et à la diffusion de documents scientifiques de niveau recherche, publiés ou non, émanant des établissements d'enseignement et de recherche français ou étrangers, des laboratoires publics ou privés. 


\section{High temperature spin-driven multiferroicity in ludwigite chromocuprate $\mathrm{Cu}_{2} \mathrm{CrBO}_{5}$}

Françoise Damay ${ }^{*}$, Jonas Sottmann ${ }^{2}$, François Fauth $^{3}$, Emmanuelle Suard ${ }^{4}$, Antoine Maignan $^{2}$, Christine Martin ${ }^{2}$

${ }^{1}$ Université Paris-Saclay, Laboratoire Léon Brillouin, CEA-CNRS UMR 12, 91191 GIF-SURYVETTE, France

francoise.damay@cea.fr

${ }^{2}$ Normandie Univ, ENSICAEN, UNICAEN, CNRS, CRISMAT, 14000 CAEN, France

${ }^{3}$ CELLS-ALBA Synchrotron, Carrer de la Llum 2-26, 08290 Cerdanyola del Vallès, BARCELONA, Spain

${ }^{4}$ Institut Laue Langevin, 6 rue Jules Horowitz, BP 156, 38042 GRENOBLE CEDEX 9, France

\section{ABSTRACT}

We report spin-driven multiferroicity above $100 \mathrm{~K}$ in the ludwigite $\mathrm{Cu}$ (II) oxyborate $\mathrm{Cu}_{2} \mathrm{CrBO}_{5}$. Spontaneous polarization, which reaches $35 \mu \mathrm{C} . \mathrm{m}^{-2}$ at $5 \mathrm{~K}$, appears below $120 \mathrm{~K}$, concomitantly with an incommensurate antiferromagnetic order and complex magnetodielectric effects. In magnetically induced ferroelectrics, multiferroicity usually appears at low temperature, because of the competing magnetic exchanges needed to stabilize a magnetic spiral : the remarkably high transition temperature observed in $\mathrm{Cu}_{2} \mathrm{CrBO}_{5}$ originates from the presence of strong $\mathrm{Cu}$ $\mathrm{O}-\mathrm{Cu}$ magnetic super-exchange interactions, which are not weakened by $\mathrm{Cu} / \mathrm{Cr}$ cationic disorder. Our result provides an important contribution to the search for high temperature spindriven multiferroics amongst low-dimensional cuprates. 


\section{Introduction}

To understand and optimize the coupling between magnetic and dielectric properties in multiferroics is one of the enduring challenge of condensed matter physics [1], [2]. Amongst the most promising multiferroic compounds are spin-driven ferroelectrics, in which ferroelectricity emerges concomitantly with a non-collinear spiral magnetic order breaking inversion symmetry [3]. Different microscopic mechanisms are at play depending on whether this complex magnetic ordering is cycloidal [4] or helicoidal [5], but in both cases, a strong coupling between the ferroic parameters is expected, hence their high potential for applications [6]. The design of spiral magnetic order is not straightforward, however, as it often relies on the existence of competing (frustrated) magnetic interactions, which also means that such orders ordinarily occur at low temperature, typically below $40 \mathrm{~K}$ [7]. To overcome this issue, compounds with large magnetic super-exchange interactions have been studied, as, for instance, hexaferrites, in which magnetic super-exchange between spin blocks can be tuned to produce long-wavelength magnetic structures close to or above room temperature (RT), and large magnetoelectric effects [8], [9], [10]. Another example is cupric oxide $\mathrm{CuO}$, with one of the largest Curie temperature $\left(\mathrm{T}_{\mathrm{C}}\right)$ amongst spin-driven multiferroics so far, $\sim 230 \mathrm{~K}$ [11], owing to the presence of a strong magnetic super-exchange $\mathrm{J} \sim 700 \mathrm{~K}$. Yet, $\mathrm{CuO}$ is ferroelectric in a narrow temperature range of about $20 \mathrm{~K}$ only, which corresponds to the range of existence of its spiral magnetic order : this serious limitation calls for better candidates.

As rich as that of silicates or phosphates, borate chemistry has always provided interesting structural frameworks [12], with, sometimes, unique functionalities, especially in non-linear optics [13]. A notorious oxyborate crystal structure for transition metals (TM) is for instance the ludwigite, of formula $\mathrm{M}_{2} \mathrm{M}^{\prime} \mathrm{BO}_{5}$ ( $\mathrm{M}$ and $\mathrm{M}^{\prime}$ being divalent and trivalent $\mathrm{TM}$, respectively). Its intricate framework of edge-sharing TM octahedra, prone to frustration, has been studied in the past for a wide variety of uncommon features, including mixed valence and dimerization [14], [15], [16], [17], magnetic sub-lattices decoupling [18], [19], ferroelectricity [20] and for 
its potential use in lithium-ion battery [21]. Literature on heterometallic copper ludwigites $\mathrm{Cu}_{2} \mathrm{M}^{\prime} \mathrm{BO}_{5}\left(\mathrm{M}^{\prime}=\mathrm{Al}, \mathrm{Fe}, \mathrm{Ga}, \mathrm{Mn}\right)$ is in contrast somewhat scarcer. Indeed, $\mathrm{Cu} / \mathrm{M}^{\prime}$ ions nonrandom distribution over at least two out of the four crystallographically distinct TM sites of the ludwigite structure is always found to be an issue [22], [23], [24], [25], which, combined with the complex geometry of the magnetic exchange paths [26], is known to affect physical properties [27], [28] and hinder reproducibility [29].

To the best of our knowledge, ludwigite $\mathrm{Cu}_{2} \mathrm{CrBO}_{5}$ has only been investigated up to now for its redox activity [21]. In this article, we show that $\mathrm{Cu}_{2} \mathrm{CrBO}_{5}$ is a remarkable example amongst copper ludwigites of a perfect cationic order between $\mathrm{Cu}(\mathrm{II})$ and $\mathrm{Cr}(\mathrm{III})$ species, and the first instance in this family of a spin-driven multiferroic above $100 \mathrm{~K}$ with complex magnetodielectric properties. Perpendicular chains of strongly interacting magnetic spins, weakly coupled, are proposed to explain the complex non-centrosymmetric magnetic order at the origin of the spin driven multiferroic properties.

\section{Experimental Methods}

$\mathrm{Cu}_{2} \mathrm{CrBO}_{5}$ was prepared starting from a mixture of $2 \mathrm{CuO} / 0.5 \mathrm{Cr}_{2} \mathrm{O}_{3} / 0.5 \mathrm{~B}_{2} \mathrm{O}_{3}\left({ }^{11} \mathrm{~B}\right.$ enriched), heated in air at $900^{\circ} \mathrm{C}$ for 24 hrs. An impurity of $\mathrm{CrBO}_{3}(\sim 0.5 \mathrm{wt} \%)$ was identified.

Synchrotron X-ray powder diffraction (SXRPD) experiments were performed between $10 \mathrm{~K}$ and $260 \mathrm{~K}$ at BL04-MSPD at ALBA synchrotron (Barcelona, Spain) $(\lambda=0.44296 \AA$ ) [30]. $\mathrm{Cu}_{2} \mathrm{CrBO}_{5}$ powders were $20 \mu \mathrm{m}$ sieved and filled in $0.5 \mathrm{~mm} \varnothing$ borosilicate capillaries. Diffractograms were collected using the Position Sensitive Detector Mythen. Neutron powder diffraction (NPD) experiments were performed at room temperature on the D2B high-resolution diffractometer $(\lambda=1.5946 \AA$ ), at ILL (Grenoble, France), and between $1.5 \mathrm{~K}$ and $300 \mathrm{~K}$ on the G4.1 diffractometer $(\lambda=2.426 \AA ̊$ ), at LLB-Orphée (Gif-sur-Yvette, France). Rietveld refinements were performed using the Fullprof Suite [31]. 
Magnetic susceptibility $(\chi)$ was derived from magnetization data recorded in a field of $1 \mathrm{~T}$, on warming from 5 to $400 \mathrm{~K}$ after a zero-field cooling (MPMS, Quantum Design). Isothermal magnetic field $(\mathrm{H})$ dependent magnetization $(\mathrm{M})$ loops were recorded using the $\mathrm{AC}$ measurement system of a 9 T Physical Properties Measurement System (PPMS, Quantum Design). A homemade sample probe inserted in the PPMS was used to measure the dielectric permittivity $\left(\varepsilon^{\prime}\right)$ and the electric polarization $(\mathrm{P})$. For that purpose, square thin platelets $(2 \times 2$ $\mathrm{x} 0.5 \mathrm{~mm}$ ) were cut from the reacted bars. The electrical contacts were deposited on the opposite largest faces using silver paint. The electret was soldered to the sample probe using $\mathrm{Cu}$ wires. $\varepsilon^{\prime}$ was measured as a function of T or $\mathrm{H}$ using a LCR meter (Agilent 4284A) whereas P was obtained by integrating the pyroelectric current collected via an electrometer (Keithley 6514A). For the $\mathrm{P}(\mathrm{T})$ curves, the data were collected upon warming at $4 \mathrm{~K} \cdot \mathrm{min}^{-1}$.

\section{Results}

$\mathrm{Cu}_{2} \mathrm{CrBO}_{5}$ crystallizes at RT with the monoclinic space group $P 2{ }_{1} / c(\# 14, a=3.05487(2) \AA, b$ $=12.18070(8) \AA, c=9.41432(7) \AA$ and $\left.\beta=94.5602(4)^{\circ}\right)$, like $\mathrm{Cu}$-based ludwigites $\mathrm{Cu}_{2} \mathrm{FeBO}_{5}$ and $\mathrm{Cu}_{2} \mathrm{GaBO}_{5}$ [23]. Rietveld refinements are shown in Figure S1, and corresponding structural parameters are given in Tables S1, S2 and S3. Its framework can be described by TM oxygen polyhedra sharing edges to form zigzag walls, themselves connected to each other through apexes. These walls delimit triangular tunnels occupied by boron atoms (Figure 1a), with typical B-O bond lengths 1.35-1.37(1) $\AA$ [23]. A few specifics of the $\mathrm{Cu}_{2} \mathrm{CrBO}_{5}$ structure, however, are noteworthy. A major structural difference lies in the shift of the $\mathrm{Cu} 1$ position to a $2 c\left(0 \frac{1}{2} 2\right)$ site in $\mathrm{Cu}_{2} \mathrm{CrBO}_{5}$, which flattens the usually strongly corrugated $\mathrm{Cu}$ chains found in ludwigites. Moreover, no $\mathrm{Cu} / \mathrm{Cr}$ mixing is observed on the TM sites, in contrast with other heterometallic copper ludwigites. In $\mathrm{Cu}_{2} \mathrm{CrBO}_{5}$, the oxygen coordination around all three $\mathrm{Cu}$ sites is $(4+2)$, in agreement with a Jahn-Teller ion like $\mathrm{Cu}(\mathrm{II})$, with the axial $\mathrm{Cu}-\mathrm{O}$ bonds being $\sim 20$ to $\sim 50 \%$ longer than the equatorial ones (Table S2). $\mathrm{CrO}_{6}$ octahedra are very regular in 
contrast, with the $\mathrm{Cr}-\mathrm{O}$ bonds being equal within a few \% (Table $\mathrm{S} 2$ ). Based on those considerations, the crystal structure of $\mathrm{Cu}_{2} \mathrm{CrBO}_{5}$ can be described as chains, running along $b$, of $\mathrm{CuO}_{4}$ squares sharing edges or corners, and connected through their edges or corners to chains (parallel to $a$ ) of edge-sharing $\mathrm{CrO}_{6}$ octahedra (Figure 1b). The shortest distance between $\mathrm{TM}$ corresponds to $\mathrm{CuO}_{4}$ sharing edges ( $\mathrm{Cu} 1-\mathrm{Cu} 3 \sim 2.80 \AA$, Table $\mathrm{S} 3$ ), forming trimerlike motifs (thick red segments on Figure 1a).

A

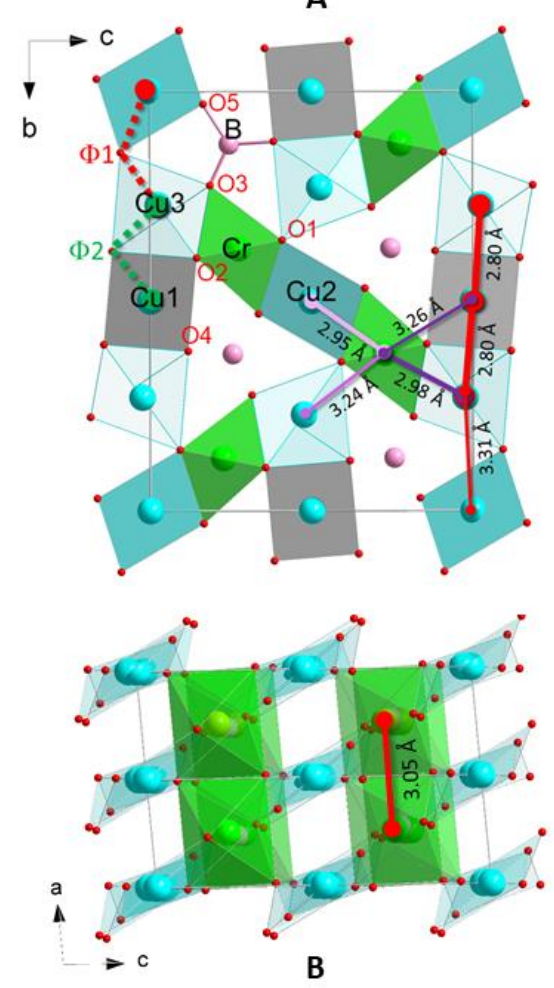

C

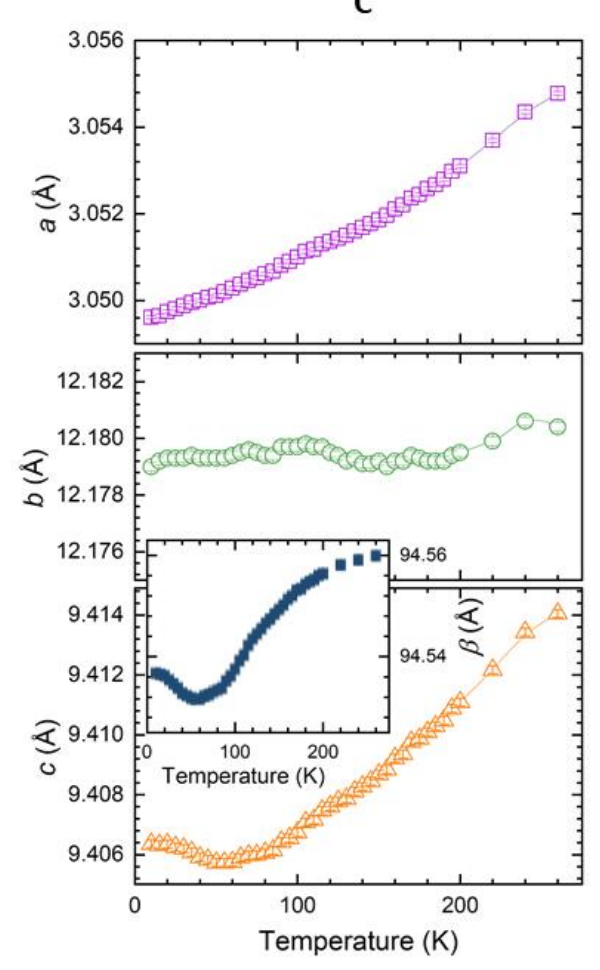

Figure 1. Projections of the monoclinic $P 2_{1} / c$ crystal structure of $\mathrm{Cu}_{2} \mathrm{CrBO}_{5}$ along $a(\mathrm{~A})$ or along $b(\mathrm{~B}) . \mathrm{Cu}$ atoms are in blue, $\mathrm{Cr}$ in green, $\mathrm{B}$ in pink and $\mathrm{O}$ in red. Distances between transition metals at RT are indicated, as well as the $\mathrm{Cu}-\mathrm{O}-\mathrm{Cu}$ angles $\Phi_{1}$ and $\Phi_{2}$. C illustrates the temperature evolution of the cell parameters $a, b$, and $c$, and of the monoclinic angle $\beta$ (inset) (from SXRPD Rietveld refinements).

The $\mathrm{Cu}_{2} \mathrm{CrBO}_{5}$ crystal structure is stable with decreasing temperature; it remains monoclinic $P 2{ }_{1} / c$ down to $10 \mathrm{~K}$, the lattice parameters decreasing with a less than $0.1 \%$ variation between 
$275 \mathrm{~K}$ and $10 \mathrm{~K}$ (Figure 1c). Slight increases of the $c$ parameter and of the monoclinic distortion are observed, however, below $60 \mathrm{~K}$ (inset of Figure 1c).

Figure 2 a shows the temperature evolution of the zero-field cooled $(z f c)$ magnetic susceptibility of $\mathrm{Cu}_{2} \mathrm{CrBO}_{5}$ in $1 \mathrm{~T}$. A susceptibility maximum is clearly seen at $\mathrm{T}_{\mathrm{N}}=117 \mathrm{~K}$, suggesting a transition to an antiferromagnetic state. Above $\mathrm{T}_{\mathrm{N}}$, the susceptibility does not follow a CurieWeiss law in the temperature range investigated $(T<400 \mathrm{~K}$, inset of Figure 2a), which could be due to low-dimensional effects or short range magnetic ordering, and prevented us from extracting a meaningful $\Theta_{\mathrm{CW}}$. At $119 \mathrm{~K}$, concomitantly with the magnetic transition, a $\lambda$-like peak is observed on the zero-field dielectric constant $\varepsilon^{\prime}$ (Figure $2 b$, left axis), and is accompanied by a step on the dielectric loss, whose low values indicate very small losses in the vicinity of the transition temperature (Figure $2 b$, right axis). This transition is frequencyinvariant over the $f$-range studied ( $f=5$ to $100 \mathrm{kHz}$, not shown), thus excluding spurious experimental effects. Figure $2 \mathrm{c}$ shows the evolution with temperature of the electric polarization $\mathrm{P}$ obtained from measurements of the pyroelectric current. A finite $\mathrm{P}$ is measured in zero magnetic field below $122 \mathrm{~K}$, and down to $5 \mathrm{~K}$, where it reaches $\sim 35 \mu \mathrm{C} . \mathrm{m}^{-2}$ for a poling field of $181.8 \mathrm{kV} \cdot \mathrm{m}^{-1}$. P can be switched by inverting the sign of the poling electric field, unambiguously confirming the ferroelectric nature of $\mathrm{Cu}_{2} \mathrm{CrBO}_{5}$ in its magnetically ordered state. The $\varepsilon^{\prime}(\mathrm{T})_{\mathrm{H}}$ curves (Figure $2 \mathrm{~d}$ ) reveal a clear magnetodielectric effect : as H increases, the dielectric peak shifts to lower temperature (-4 K between 0 and $9 \mathrm{~T}$ ), with, up to $5 \mathrm{~T}$, an increase of the peak amplitude. Above $5 \mathrm{~T}$, the $\varepsilon$ ' peak starts to broaden markedly with $\mathrm{H}$, its amplitude decreasing concomitantly. Further measurements versus magnetic field $\mathrm{H}$ were therefore performed to characterize this effect. Three different behaviors are identified, as illustrated by the magnetodielectric curves $\mathrm{MDE}=\left(\left(\varepsilon^{\prime} \mathrm{H}^{-} \varepsilon^{\prime}{ }_{0}\right) / \varepsilon{ }^{\prime}\right)(\mathrm{H})$ of Figure $2 \mathrm{e}$; just above $\mathrm{T}_{\mathrm{N}}$, there is no magnetodielectric effect; just below $\mathrm{T}_{\mathrm{N}}$, a negative MDE is observed at $116 \mathrm{~K}$, while a positive MDE is measured at $112 \mathrm{~K}$. On the latter, a maximum of $0.6 \%$ is reached at $+/-5.9 \mathrm{~T}$. This 
characteristic magnetic field of $5.9 \mathrm{~T}$ at $112 \mathrm{~K}$ corresponds to a change of slope on the magnetization $\mathrm{M}(\mathrm{H})$ curves, more clearly identified on the $\mathrm{dM} / \mathrm{dH}(\mathrm{H})$ curves (Figure S2), and is indicative of a metamagnetic transition in the vicinity of $\mathrm{T}_{\mathrm{N}}$, more generally suggesting for $\mathrm{Cu}_{2} \mathrm{CrBO}_{5}$ a rich multiferroic phase diagram to explore.
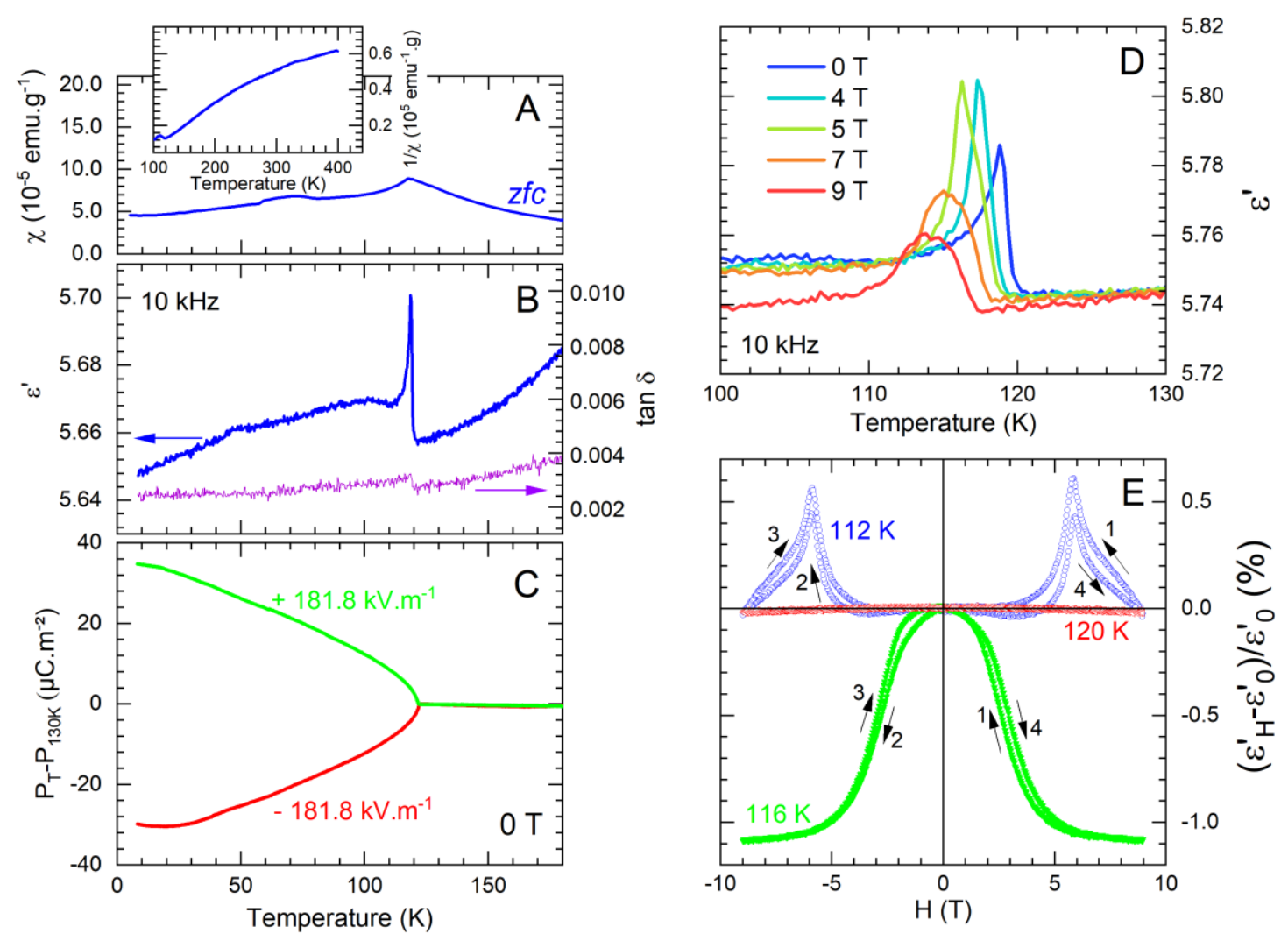

Figure 2. Temperature (T) dependence of the $z f c$ magnetic susceptibility $\chi$ in $1 \mathrm{~T}(\mathrm{~A})$. The small bump observed around $70 \mathrm{~K}$ is of unknown origin. The inset shows $1 / \chi(\mathrm{T})$ in $0.01 \mathrm{~T}$, in the range $100-400 \mathrm{~K}$. Temperature evolution of the dielectric constant $\varepsilon^{\prime}$ (B-right axis), of the corresponding loss ( $\tan \delta$ ) (B-right axis) at $10 \mathrm{kHz}$ in $0 \mathrm{~T}$, and of the spontaneous polarization $\Delta P$ after $+/-181.8 \mathrm{kV} . \mathrm{m}^{-1}$ electric field poling (C). Magnetic field evolution of the dielectric constant $\varepsilon^{\prime}(\mathrm{T})$ measured at $10 \mathrm{kHz}$ between 0 and $9 \mathrm{~T}$ (D). $\mathrm{E}$ shows the magnetodielectric coefficient MDE defined as $\left(\left(\varepsilon^{\prime}{ }^{-}-\varepsilon_{0}^{\prime}\right) / \varepsilon_{0}^{\prime}\right)$ versus $\mathrm{H}$ at $112 \mathrm{~K}, 116 \mathrm{~K}$ and $120 \mathrm{~K}$.

A proper understanding of the microscopic mechanism behind the multiferroic properties of $\mathrm{Cu}_{2} \mathrm{CrBO}_{5}$ requires knowledge of its magnetic ordering. Cold neutron diffraction experiments were performed down to $1.5 \mathrm{~K}$ (Figure $3 \mathrm{a}$ ). Below $\mathrm{T}_{\mathrm{N}}$, new Bragg peaks of magnetic origin 
can be seen on the neutron diffractograms, whose incommensurate Q positions vary with temperature down to $30 \mathrm{~K}$ (inset of Figure 3a) and then remain invariant down to $1.5 \mathrm{~K}$, but still incommensurate. Indexing of these peaks actually proved to be challenging, owing to the limited number of magnetic peaks. Several solutions with similar reliability factor could be obtained for the magnetic propagation vector k. One of them, with only one incommensurate

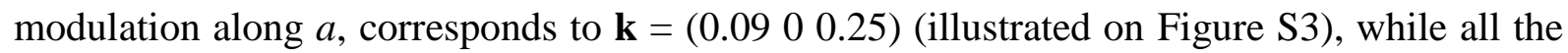
other solutions involve at least two incommensurate modulations along $b$ and $c$ (or $a$ and $c$ ). It is not possible to characterize further the magnetic ordering at that stage, because of the low symmetry of the crystal structure, the existence of four distinct magnetic sites, and the uncertainty on the number of modulations for $\mathbf{k}$. The fact that the magnetic state is ferroelectric nevertheless suggests a long wavelength helicoidal or cycloidal magnetic structure, rather than a spin amplitude modulation, arguably involving both $\mathrm{Cr}$ and $\mathrm{Cu}$ spins.

This incommensurate magnetic propagation vector confirms that the ludwigite framework of $\mathrm{Cu}_{2} \mathrm{CrBO}_{5}$ is host to frustration. Owing to its different crystal structure, the magnetic topology in $\mathrm{Cu}_{2} \mathrm{CrBO}_{5}$ is distinct from that of other ludwigites, and can be seen as two perpendicular sublattices made of spin chains. One chain is made of $\mathrm{Cu}$ spins and runs along $b$; because it is made of an alternation of $\mathrm{CuO}_{4}$ units sharing corners or edges, magnetic interactions in these chains are either of the super-exchange type (through the angle $\Phi 1$ on Figure 1a) or directexchange like (through the angle $\Phi 2$ on Figure 1a). This chain thus corresponds to an alternation of magnetic exchanges $-\mathrm{J}_{\Phi_{1}-}-\mathrm{J}_{\Phi_{1}-} \mathrm{J}_{\Phi_{2}-} \mathrm{J}_{\Phi_{2}}$ - between $\mathrm{Cu}$ atoms (Figure $3 \mathrm{~b}$ ). The second magnetic sublattice is made of $\mathrm{Cr}$ chains. $\mathrm{As}_{\mathrm{CrO}_{6}}$ octahedra only share edges along $a, \mathrm{Cr}-\mathrm{Cr}$ interactions are through a unique direct-exchange $\mathrm{J}_{a}$ (Figure $3 \mathrm{~b}$, in which only nearest-neighbor (NN) interactions only are considered for simplicity). A minimum of six inter-sublattice interactions have to be taken into account in addition: they involve triangular configurations in the $b c$ plane and along $a$ (Figure $3 \mathrm{~b}$ and Table S3), so that competing interactions are 
conceivable in the three directions. This will be dwelt upon further in the discussion, after considerations on $\mathrm{J}_{\Phi 1}$ and $\mathrm{J}_{\Phi 2}$.

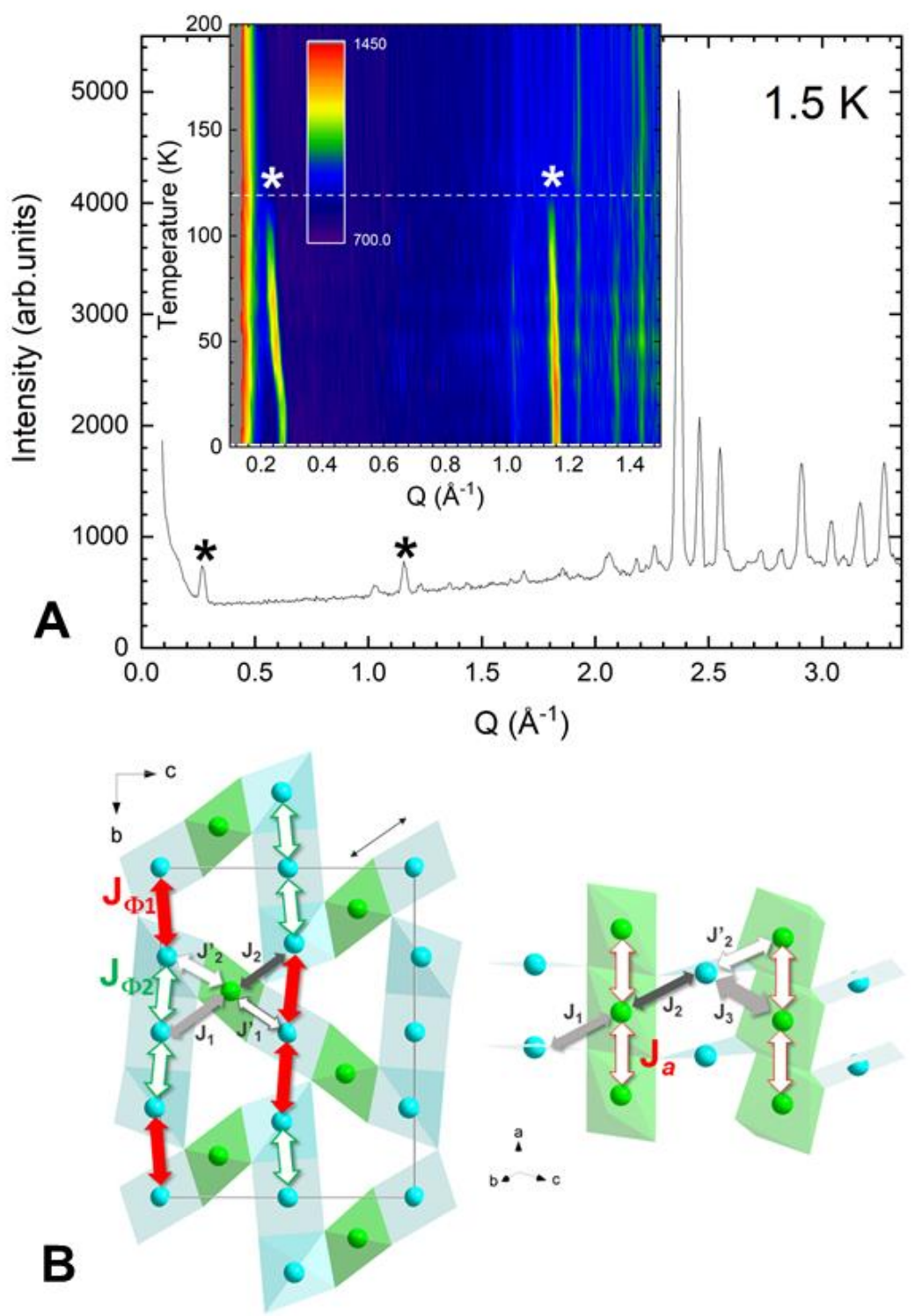

Figure 3. $\mathrm{Cu}_{2} \mathrm{CrBO}_{5}$ neutron diffraction data at $1.5 \mathrm{~K}(\mathrm{~A})$, with the inset illustrating the corresponding temperature evolution. Asterisks indicate the incommensurate Bragg magnetic peaks appearing below $\mathrm{T}_{\mathrm{N}}=120 \mathrm{~K}$. B schematizes the different magnetic exchange paths (as defined in Table S3). White (colored) arrows are for direct (super)-exchange configurations; intra-chains magnetic paths are in green or red, inter-sublattices exchange paths in dark/light grey. $\mathrm{Cu} / \mathrm{Cr}$ atoms in blue/green for clarity. The thin arrow line on the left panel indicates the direction of the polyhedral block shown on the right. 
The simultaneous occurrence of ferroelectricity and magnetic order designates copper ludwigite $\mathrm{Cu}_{2} \mathrm{CrBO}_{5}$ as a new member of the spin-driven multiferroic family. Compared with most known multiferroic compounds, $\mathrm{Cu}_{2} \mathrm{CrBO}_{5}$ exhibits in addition a high transition temperature of $120 \mathrm{~K}$, amongst the highest known, but still behind tuned hexaferrites (295 K [32]), CuO (230 $\mathrm{K}$ [11]) or $\mathrm{YBaCuFeO}_{5}\left(200 \mathrm{~K}\right.$ [33], [34]). Along $\mathrm{CuO}$, and non-oxide $\mathrm{CuBr}_{2}$ [35] or $\mathrm{Cu}_{2} \mathrm{OCl}_{2}$ [36], $\mathrm{Cu}_{2} \mathrm{CrBO}_{5}$ confirms that low-dimensional divalent copper compounds have a potential to be high-temperature multiferroics. It is therefore of interest to rationalize our findings, using the extensive knowledge built on $\mathrm{Cu}$ (II) oxides of low dimensionality, since the discovery of high- $\mathrm{T}_{\mathrm{c}}$ superconductivity in cuprates.

For more than 50 years, the Goodenough-Kanamori-Anderson (GKA) rules [37], [38] have been used to qualitatively relate magnetic exchange $\mathrm{J}$ with orbital overlap. In divalent copper oxide compounds, the $\mathrm{NN} \mathrm{Cu}-\mathrm{Cu}$ spin interaction $\mathrm{J}$ is thus expected to change from antiferromagnetic (AFM) to ferromagnetic (FM), when the angle $\Phi$ of the $\mathrm{Cu}-\mathrm{O}-\mathrm{Cu}$ bond goes from $180^{\circ}$ to $90^{\circ}$. Such a correlation has indeed been shown in a series of low-dimensional $\mathrm{Cu}$ (II) compounds [39], [40], [41], including $\mathrm{CuO} \mathrm{[11],} \mathrm{[42],} \mathrm{and} \mathrm{is} \mathrm{recalled} \mathrm{in} \mathrm{Figure} \mathrm{4.} \mathrm{In}$ $\mathrm{Cu}_{2} \mathrm{CrBO}_{5}, \mathrm{Cu}$ chains are made of edge-sharing trimer units $\left(\Phi_{2}\right.$ close to $\left.90^{\circ}\right)$, connected through corners by a $\mathrm{Cu}-\mathrm{O}-\mathrm{Cu}$ angle $\Phi_{1}$ close to $120^{\circ}$ (Figure 1a and Table S3). Using Figure 4, we can expect ferromagnetic $\mathrm{Cu}$ trimers $\left(F M \mathrm{~J}_{\Phi_{2}}\right)$, antiferromagnetically coupled through $\mathrm{J}_{\Phi 1}$ (Figure $3 b$ ). $\mathrm{J}_{\Phi 1}$ could be as high as $20 \mathrm{meV}$ in this case, which is the right order of magnitude to account for $\mathrm{T}_{\mathrm{N}}=120 \mathrm{~K}(\sim 10 \mathrm{meV})$.

For comparison with other copper ludwigites, two instances can be mentioned. In a very recent study on $\mathrm{Cu}_{2} \mathrm{MBO}_{5}(M=\mathrm{Ga}, \mathrm{Al})$ [43], authors report for $\mathrm{Cu}_{2} \mathrm{GaBO}_{5}$ a complex non-collinear long-range magnetic order, with a propagation vector $\mathbf{k}=(0.45,0,-0.7)$, below $\mathrm{T}_{\mathrm{N}}=4.1 \mathrm{~K}$. Following the GKA rules for $\mathrm{Cu}-\mathrm{O}-\mathrm{Cu}$ bonds, they suggest that, since half of the TM sites (corresponding in this case to the $\mathrm{Cu} 1$ and $\mathrm{Cr}$ sites of $\mathrm{Cu}_{2} \mathrm{CrBO}_{5}$ ) are statistically occupied by 
$1 / 3$ of the $\mathrm{Cu}^{2+}$, this disordered sublattice of $\mathrm{Cu}$ orphan spins provides only a very weak FM coupling between corner-sharing AFM units. $\mathrm{Cu}_{2} \mathrm{MnBO}_{5}$ [24], in which a $\mathbf{k}=0$ magnetic order below $\mathrm{T}_{\mathrm{N}}=92 \mathrm{~K}$ was found, is built on FM trimer units roughly coupled AFM. The overall scenario of a FM $\mathrm{J}_{\Phi 2}$ and $\mathrm{AFM} \mathrm{J}_{\Phi 1}$ seems to hold in this case, but this resemblance has to be taken with caution, as $\mathrm{Cu} / \mathrm{Mn}$ disorder, along with the Jahn-Teller nature of $\mathrm{Mn}^{3+}$, will obviously alter magnetic exchanges.

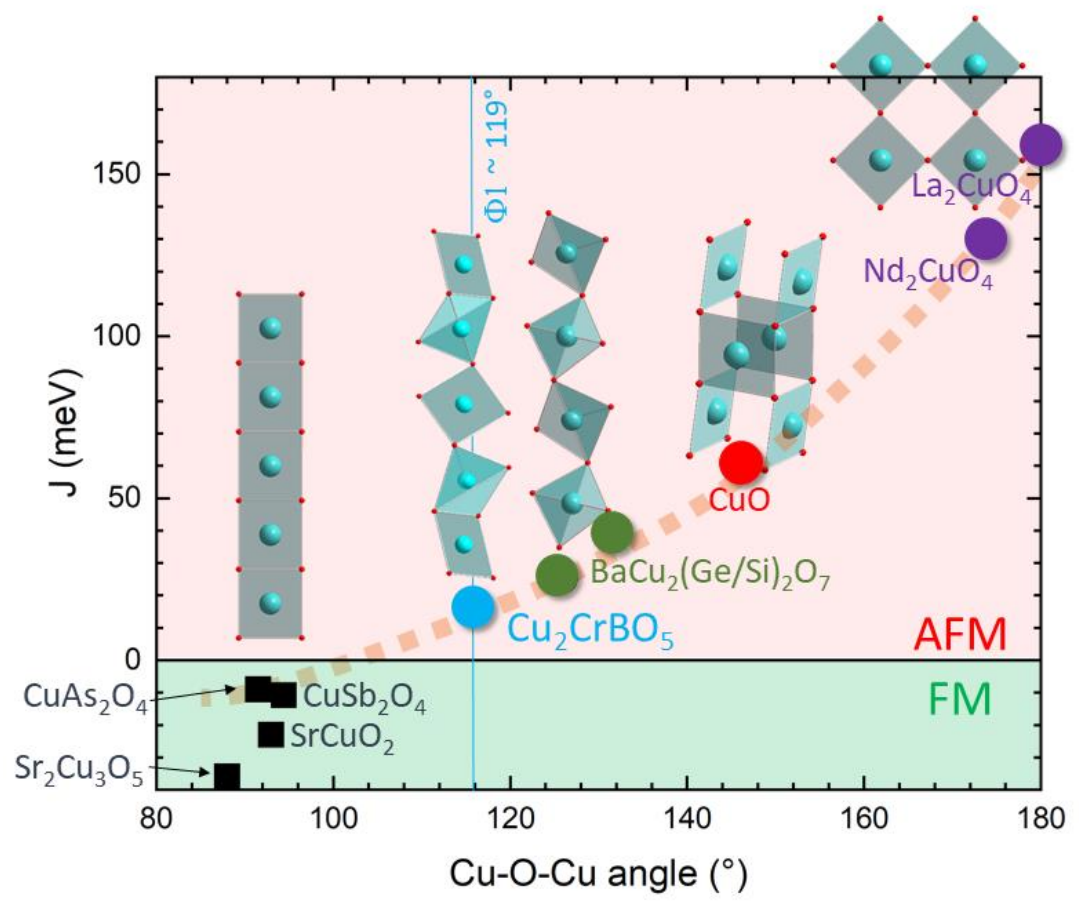

Figure 4. Evolution of the main magnetic exchange interaction $\mathrm{J}$ as a function of the $\mathrm{Cu}-\mathrm{O}-\mathrm{Cu}$ bond angle $\Phi$ in some cuprates, including $\mathrm{Cu}$ (II) oxyborate $\mathrm{Cu}_{2} \mathrm{CrBO}_{5}$ (drawn from data presented in [39], [41], [42], [44], obtained either from susceptibility measurements, neutron data or theoretical calculations). The dotted line is a guide to the eyes. The value of the predominant exchange $\mathrm{J}$ in $\mathrm{Cu}_{2} \mathrm{CrBO}_{5}$ can be estimated to be $\sim 20 \mathrm{meV}$, from the $\Phi_{1}$ value obtained from SXRPD refinements (see Figure 1a and Table S3).

The role of $\mathrm{Cr}$ chains becomes crucial because of the complex inter-sublattice pathways exemplified earlier. It is not possible to establish a hierarchy of exchange at this stage, but the modulated magnetic propagation vector tells us that one scenario is for $\mathrm{J}_{2}$ and $\mathrm{J}_{1}$ to be both $A F$, or $\mathrm{J}_{2}{ }_{2}$ and $\mathrm{J}_{1}$ to be of opposite signs. Based on the fact that $\mathrm{J}_{2}$ and $\mathrm{J}_{1}$, and $\mathrm{J}_{2}{ }_{2}$ and $\mathrm{J}_{1}{ }_{1}$ have very 
similar geometries, it is most likely that frustration arises from the phase shift between $\mathrm{Cu}$ chains. It is a similar scenario, based on two magnetic sublattices with strong intra-sublattice interactions and weakly frustrated inter-sublattice interactions, which is invoked to explain spin frustration in $\mathrm{CuO}$ [45]. Arguably, magnetic anisotropy could also be an important ingredient in the stabilization of the spiral ground state. To compare with $\mathrm{Cu}_{2} \mathrm{MnBO}_{5}$, one could argue that in $\mathrm{Cu}_{2} \mathrm{CrBO}_{5}$ the Heisenberg character of the $\mathrm{Cr}$ spins favors incommensurate orderings, an effect that disappears when axial magnetic anisotropy directs the moment, such as in a JahnTeller ion like $\mathrm{Mn}^{3+}$.

\section{Conclusion}

Our results emphasize that the ludwigite network of copper oxyborates displays the right balance of low dimension, magnetic frustration, and strong magnetic exchange, for high temperature multiferroicity. $\mathrm{Cu}_{2} \mathrm{CrBO}_{5}$ is the first member of this family to be evidenced, but other heterometallic $\mathrm{Cu}$ (II) compounds remain to be investigated, especially if the disorder issue can be controlled. Density functional calculations should prove a really useful tool to further explore this system, in particular to better apprehend the importance of the intersublattice coupling, and understand how it can be used to further optimize its multiferroic properties.

\section{AUTHOR CONTRIBUTIONS}

Sample synthesis and structural characterizations by C.M. and J.S., SXRPD experiment by J.S. and F.F., physical properties measurements by C.M. and A.M., NPD experiments by E.S. and F.D. Manuscript writing by F.D. and J.S., with constant feedback from all co-authors.

\section{ACKNOWLEDGEMENTS}


We acknowledge S. Dufourd (CRISMAT) for sample preparations and F. Veillon (CRISMAT) for the dielectric and polarization measurements. We thank N. Barrier (CRISMAT) for assistance with the crystal structure determination.

This work was partially supported by the ANR grant BORA-BORA (ANR-16-CE08-0007-01).

\section{SUPPLEMENTARY MATERIAL}

See supplementary material for Rietveld refinement of the $\mathrm{Cu}_{2} \mathrm{CrBO}_{5} \mathrm{SXRPD}_{\text {data }}$ at $260 \mathrm{~K}$ and NPD data at RT ; Magnetic field evolution of the magnetization and first field derivative of the magnetization of $\mathrm{Cu}_{2} \mathrm{CrBO}_{5}$ at different temperatures ; LeBail profile of the $\mathrm{Cu}_{2} \mathrm{CrBO}_{5}$ NPD data at $1.5 \mathrm{~K}$, and results of the SXRPD Rietveld refinement of $\mathrm{Cu}_{2} \mathrm{CrBO}_{5}$ at $260 \mathrm{~K}$ (including M-O bond lengths and selected atomic distances and angles).

\section{DATA AVAILABILITY STATEMENT}

The data that supports the findings of this study are available within the article and its supplementary material.

\section{REFERENCES}

[1] M. FIEBIG, Journal of Physics D-applied Physics 38, R123 (2005).

[2] N. A. SPALDIN and R. RAMESH, Nature Materials 18, 203 (2019).

[3] S.-W. Cheong and M. Mostovoy, Nature Materials 6, 13 (2007).

[4] H. Katsura, N. Nagaosa, and A. V. Balatsky, Physical Review Letters 95, 057205 (2005).

[5] T. ARIMA, Journal of the Physical Society of Japan 76, 073702 (2007).

[6] C. W. NAN, M. I. BichuRin, S. X. Dong, D. Viehland, and G. SRINIVASAN, Journal of Applied Physics 103, 031101 (2008).

[7] T. KIMURA, Annual Review of Materials Research 37, 387 (2007). 
[8] T. Kimura, G. LAwes, and A. P. Ramirez, Physical Review Letters 94, 137201 (2005).

[9] Y. KitAgawa, Y. HiRAoka, T. Honda, T. IshikURA, H. NAKAmURA, and T. KimuRA, Nature Materials 9, 797 (2010).

[10] K. Zhai, Y. Wu, S. P. Shen, W. Tian, H. B. CaO, Y. S. Chai, B. C. Chakoumakos, D. S. Shang, L. Q. YAn, F. W. WANG, and Y. Sun, Nature Communications 8, 51 (2017).

[11] T. Kimura, Y. SeKio, H. Nakamura, T. Siegrist, and A. P. RamireZ, Nature Materials 7, 291 (2008).

[12] P. BECKER, Zeitschrift Fur Kristallographie 216, 523 (2001).

[13] D. EimerL, L. DAVIS, S. Velsko, E. K. Graham, and A. ZAlKin, Journal of Applied Physics 62, 1968 (1987).

[14] H. STEINFInK and J. S. SwINNEA, American Mineralogist 68, 827 (1983).

[15] A. P. Douvalis, A. Moukarika, T. BaKas, G. Kallias, and V. Papaefthymiou, Journal of Physics: Condensed Matter 14, PII S0953 (2002).

[16] E. Vallejo and M. Avignon, Phys. Rev. Lett. 97, 217203 (2006).

[17] M. Mir, R. B. Guimaraes, J. C. Fernandes, M. A. Continentino, A. C.

Doriguetto, Y. P. Mascarenhas, J. Ellena, E. E. Castellano, R. S. Freitas, and L. GHIVELDER, Physical Review Letters 87, 147201 (2001).

[18] P. Bordet and E. SuARD, Physical Review B 79, 144408 (2009).

[19] J. P. AttField, J. F. Clarke, and D. A. Perkins, Physica B 180, 581 (1992).

[20] A. Maignan, F. Laine, A. Guesdon, S. Malo, F. Damay, and C. Martin, Journal of Solid State Chemistry 246, 209 (2017).

[21] J. Sottmann, L. NAtaf, L. Chaix, V. Pralong, and C. Martin, Journal of Physical Chemistry C 122, 17042 (2018).

[22] J. A. Hriljac, R. D. Brown, A. K. Cheetham, and L. C. SAtek, Journal of Solid State Chemistry 84, 289 (1990). 
[23] J. Shaefer and K. BluhM, Z. Anorg. Allg. Chem. 621, 571 (1995).

[24] E. Moshinina, C. RitTer, E. ERemin, S. Sofronova, A. KArtashev,

A. DubrovskiY, and L. BeZMATERnYKH, Journal of Physics-condensed Matter 29, 245801 (2017).

[25] R. Eremina, T. Gavrilova, E. Moshinina, I. Gilmutdinov, R. Batulin, V. GuRZHIY, V. GRINENKO, and D. InOsOV, Journal of Magnetism and Magnetic Materials 515, $167262(2020)$.

[26] S. Sofronova, E. Moshinina, I. NAZAREnKo, Y. SERyotkin, S. A. NePijko, V. Ksenofontov, K. Medjanik, A. VeligZhanin, and L. BeZMATERnyKh, Journal of Magnetism and Magnetic Materials 420, 309 (2016).

[27] G. A. Petrakovskit, L. N. Bezmaternykh, D. A. Velikanov, A. M. Vorotynov, O. A. BAyukov, and M. SchneIDER, Physics of the Solid State 51, 2077 (2009).

[28] I. I. NAZARENKo, S. N. SOFRONOVA, and E. M. MOSHKINA, Journal of Experimental and Theoretical Physics 126, 674 (2018).

[29] M. A. Continentino, J. C. Fernandes, R. B. Guimares, H. A. Borges, A. Sulpice, J. L. Tholence, J. L. Siqueira, J. B. M. Da Cunha, and C. A. Dos Santos, European Physical Journal B 9, 613 (1999).

[30] F. Fauth, R. Boer, F. Gil-Ortiz, C. Popescu, O. Vallcorba, I. Peral, D. Fulla, J. BenaCh, and J. JUANHuiX, European Physical Journal Plus 130, 160 (2015).

[31] J. Rodriguez-Carvajal, Physica B 192, 55 (1993).

[32] V. Kocsis, T. Nakajima, M. Matsuda, A. KikKawa, Y. KaneKo, J. Takashima, K. Kakurai, T. Arima, F. Kagawa, Y. Tokunaga, Y. TokURA, and Y. Taguchi, Nature Communications 10, 1247 (2019).

[33] B. Kundys, A. Maignan, and C. Simon, Applied Physics Letters 94, 072506 (2009).

[34] T. Shang, E. Canevet, M. Morin, D. Sheptyakov, M. T. Fernandez-Diaz, E. Pomjakushina, and M. Medarde, Science Advances 4, eaau6386 (2018). 
[35] L. ZhaO, T. L. Hung, C. C. Li, Y. Y. Chen, M. K. Wu, R. K. Kremer, M. G. Banks, A. Simon, M. H. Whangbo, C. LeE, J. S. KIM, I. KIM, and K. H. KIM, Advanced Materials 24, 2469 (2012).

[36] L. Zhao, M. T. FernandeZ-Diaz, L. H. TJeng, and A. C. KomareK, Science Advances 2, UNSP e1600353 (2016).

[37] P. W. ANDERSON, Solid State Physics 14, 99 (1963).

[38] J. B. Goodenough, Physical Review 117, 1442 (1960).

[39] Y. Mizuno, T. Tohyama, S. Maekawa, T. Osafune, N. Motoyama, H. Eisaki, and S. UCHIDA, Physical Review B 57, 5326 (1998).

[40] T. Shimizu, T. Matsumoto, A. Goto, K. Yoshimura, and K. Kosuge, Journal of the Physical Society of Japan 72, 2165 (2003).

[41] M. Matsuda, J. Ma, V. O. Garlea, T. Ito, H. Yamaguchi, K. OKA, S.-L. DRECHSLER, R. YADAV, L. HozOI, H. Rosner, R. SCHUMANN, R. O. KuZIAN, and S. Nishimoto, Phys. Rev. B 100, 104415 (2019).

[42] X. Rocquefelte, K. Schwarz, and P. Blaha, Scientific Reports 2, 759 (2012).

[43] A. A. Kulbakov, R. Sarkar, O. Janson, S. Dengre, T. Weinhold, E. M. Moshina, P. Y. Portnichenko, H. Luetkens, F. Yokaichiya, A. S. Sukhanov, R. M. EREMINA, P. Schlender, A. SchneIDEwind, H. H. KlAusS, and D. S. InOsov, Destruction of long-range magnetic order in an external magnetic field and the associated spin dynamics in $\mathrm{Cu}_{2} \mathrm{GaBO}_{5}$, arXiv:2011.05819 [cond-mat.str-el], 2020.

[44] T. Shimizu, T. Matsumoto, A. Goto, T. V. C. Rao, K. Yoshimura, and K. Kosuge, Physical Review B 68, 224433 (2003).

[45] G. X. Jin, K. CAO, G. C. GuO, and L. X. He, Physical Review Letters 108, 187205 (2012). 


\section{Supplementary Material}

\section{High temperature spin-driven multiferroicity in ludwigite chromocuprate $\mathrm{Cu}_{2} \mathrm{CrBO}_{5}$}

Françoise Damay, Jonas Sottmann, François Fauth, Emmanuelle Suard, Antoine Maignan, Christine Martin

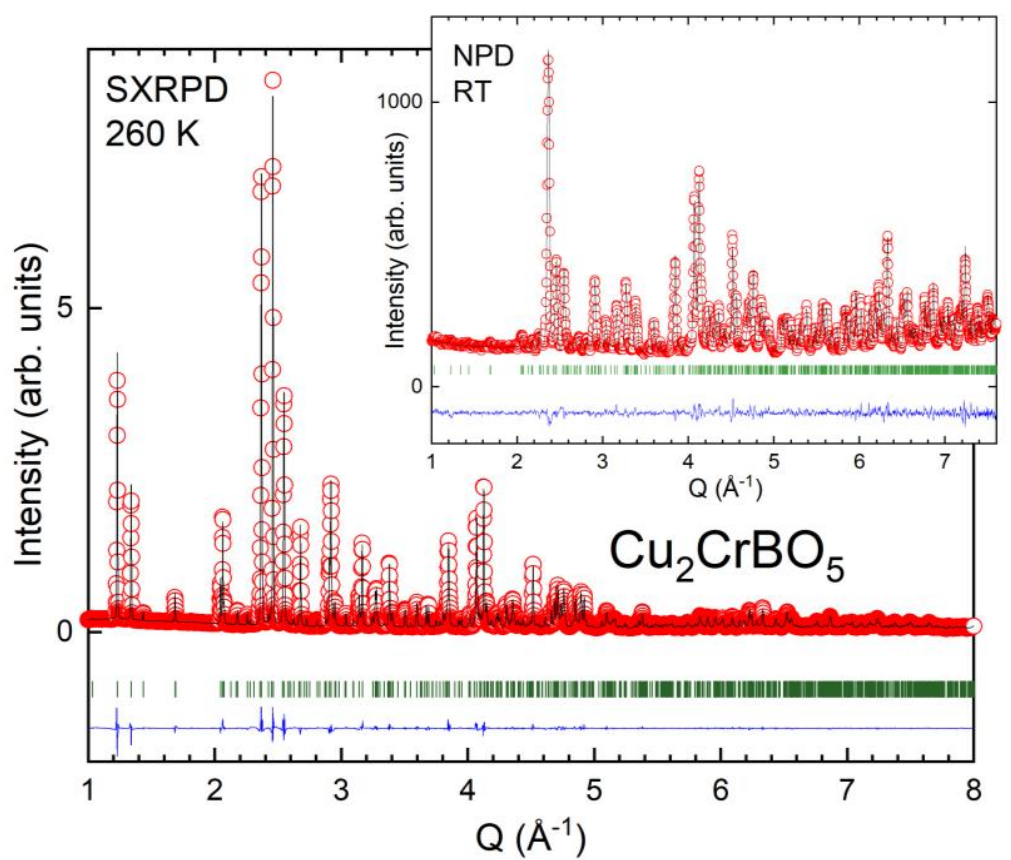

Figure S1. Rietveld refinement of the $\mathrm{Cu}_{2} \mathrm{CrBO}_{5} \mathrm{SXRPD}$ data $(\lambda=0.44296 \AA)$ at $260 \mathrm{~K}$ and NPD data $(\lambda=1.5946 \AA)$ at RT (experimental data: open red circles, calculated profile: continuous line, allowed Bragg reflections: vertical green marks. The difference between the experimental and calculated profiles is displayed at the bottom of each graph as a blue line). 


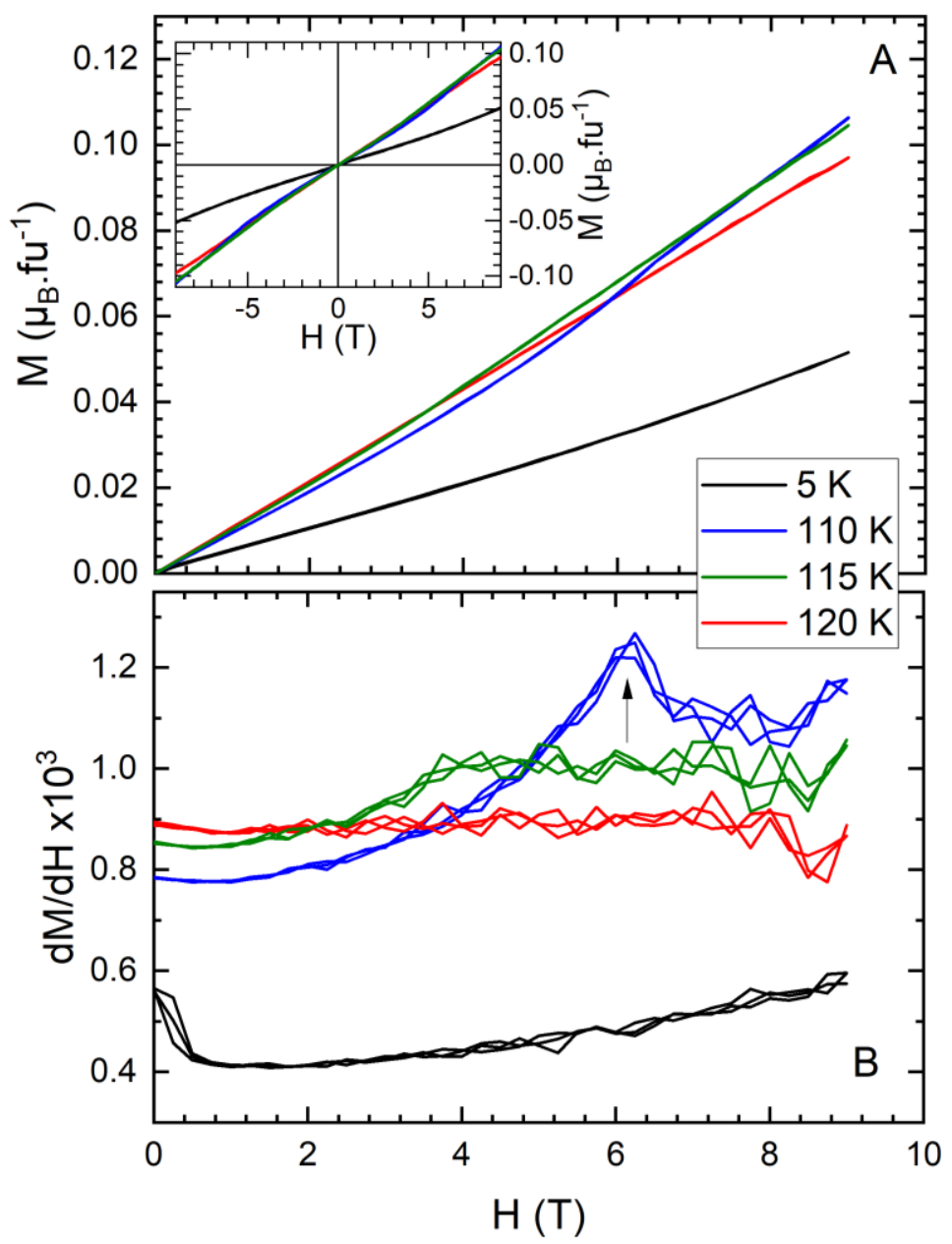

Figure S2. Magnetic field evolution (A) and corresponding first magnetic field derivative (B) of the magnetization $\mathrm{M}_{\text {of }} \mathrm{Cu}_{2} \mathrm{CrBO}_{5}$ at different temperatures $(5 \mathrm{~K}, 110 \mathrm{~K}, 115 \mathrm{~K}$ and $120 \mathrm{~K})$. 


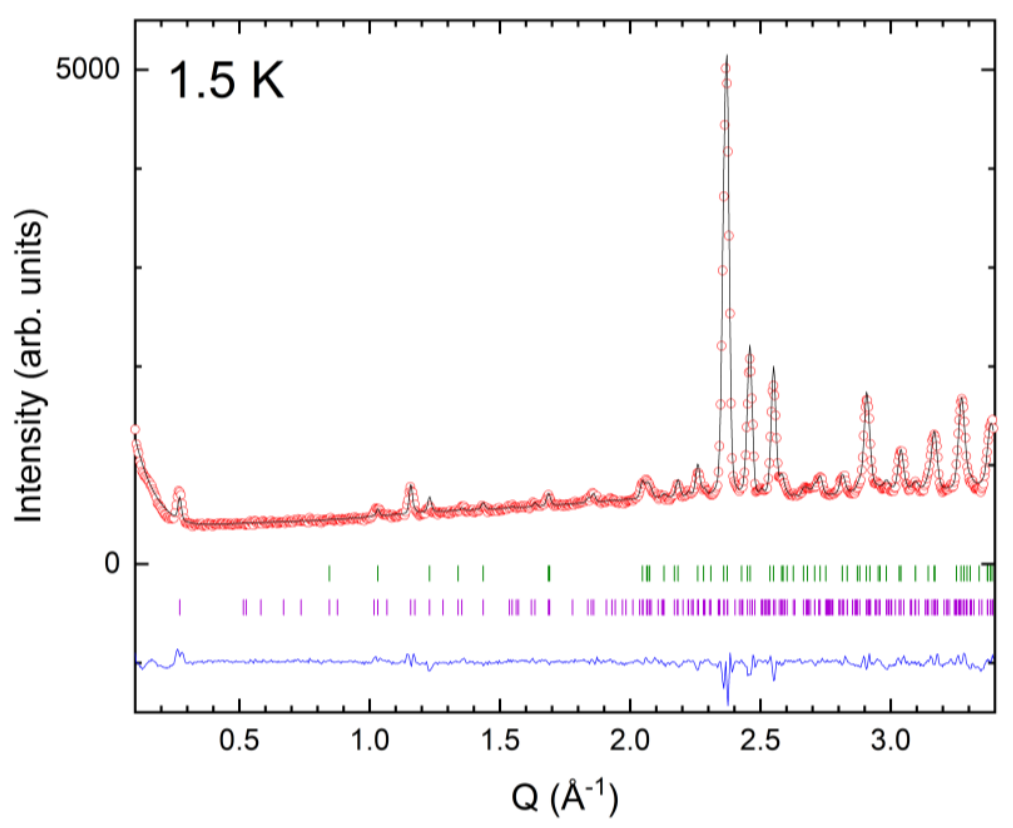

Figure S3. LeBail profile of the $\mathrm{Cu}_{2} \mathrm{CrBO}_{5} \mathrm{NPD}$ data $(\lambda=2.426 \AA)$ at $1.5 \mathrm{~K}$. The chosen propagation vector in that case is $\mathbf{k}=(0.096(3), 0,0.25)$ (experimental data: open red circles, calculated profile: continuous line, allowed Bragg (magnetic Bragg) reflections: vertical green (purple) ticks. The difference between the experimental and calculated profiles is displayed at the bottom of each graph as a blue line). 
Table S1. Results of the SXRPD Rietveld refinement of $\mathrm{Cu}_{2} \mathrm{CrBO}_{5}$ at $260 \mathrm{~K}$ (SG: $P 2{ }_{1} / c, a=$ 3.05433(3) $\AA$, $b=12.1788(1) \AA, c=9.4129(1) \AA$ and $\beta=94.5605(6)^{\circ}$. Cell volume 349.032(6) $\AA^{3}$. $\left.\mathrm{R}_{\text {Bragg }}=1.8 \% ; \chi^{2}=17.6\right)$. Atom labelling corresponds to that of Figure 1a. Thermal displacement parameters $B_{\text {iso }}$ were constrained to be equal for all oxygen atoms. Anisotropic strain (strain_model $=2[31]$ ) was introduced in the refinement.

\begin{tabular}{llllll}
\hline Atom & Site & $x$ & $y$ & $z$ & $B_{\text {iso }}\left(\AA^{2}\right)$ \\
\hline $\mathrm{Cu} 1$ & $2 c$ & 0 & 0.5 & 0 & $0.28(2)$ \\
$\mathrm{Cu} 2$ & $2 a$ & 0 & 0.5 & 0.5 & $0.20(2)$ \\
$\mathrm{Cu} 3$ & $4 e$ & $0.9979(3)$ & $0.2709(5)$ & $0.0244(7)$ & $0.20(2)$ \\
$\mathrm{Cr}$ & $4 e$ & $0.4959(4)$ & $0.3750(1)$ & $0.2738(1)$ & $0.15(2)$ \\
$\mathrm{B}$ & $4 e$ & $0.526(3)$ & $0.3744(9)$ & $0.7459(8)$ & $0.4(1)$ \\
$\mathrm{O} 1$ & $4 e$ & $0.015(1)$ & $0.1453(3)$ & $0.9095(4)$ & $0.03(3)$ \\
$\mathrm{O} 2$ & $4 e$ & $0.975(1)$ & $0.3966(3)$ & $0.1438(3)$ & $0.03(3)$ \\
$\mathrm{O} 3$ & $4 e$ & $0.432(2)$ & $0.2232(3)$ & $0.1853(4)$ & $0.03(3)$ \\
$\mathrm{O} 4$ & $4 e$ & $0.716(1)$ & $0.3818(4)$ & $0.8819(3)$ & $0.03(3)$ \\
$\mathrm{O} 5$ & $4 e$ & $0.458(2)$ & $0.0312(3)$ & $0.1650(4)$ & $0.03(3)$ \\
\hline
\end{tabular}

Table S2. M-O bond lengths in the $\mathrm{TMO}_{6}$ polyhedra of $\mathrm{Cu}_{2} \mathrm{CrBO}_{5}$ at $260 \mathrm{~K}$ (from SXRPD refinement results). In italic are shown bond lengths $>2.35 \AA$ (not taken into account in the average calculation).

\begin{tabular}{lllll}
\hline & $\mathrm{Cu} 1(2 c)$ & $\mathrm{Cu} 2(2 \mathrm{a})$ & $\mathrm{Cu} 3(4 e)$ & $\mathrm{Cr}(4 e)$ \\
\hline TM-O & $\mathrm{O} 2: 1.855(3) \times 2$ & $\mathrm{O} 1: 1.966(4) \times 2$ & $\mathrm{O} 1: 1.877(3)$ & $\mathrm{O} 2: 1.943(4)$ \\
distance $(\AA)$ & $\mathrm{O} 4: 1.977(4) \times 2$ & $\mathrm{O} 5: 2.042(4) \times 2$ & $\mathrm{O} 2: 1.904(3)$ & $\mathrm{O} 1: 1.972(4)$ \\
& $04: 2.911(4) \times 2$ & $05: 2.388(5) \times 2$ & $\mathrm{O} 3: 2.018(4)$ & $\mathrm{O} 5: 1.990(4)$ \\
& & & $\mathrm{O} 4: 2.045(4)$ & $\mathrm{O} 2: 1.998(4)$ \\
& & & $O 3: 2.455(5)$ & $\mathrm{O} 3: 2.029(4)$ \\
& & & $O 4: 2.983(4)$ & $\mathrm{O} 1: 2.036(4)$ \\
\hline Average $(\AA)$ & $1.916(4)$ & $2.004(4)$ & $1.961(4)$ & $1.995(4)$ \\
\hline
\end{tabular}


Table S3. Selected atomic distances and angles in $\mathrm{Cu}_{2} \mathrm{CrBO}_{5}$ at $260 \mathrm{~K}$ (from SXRPD refinement results). Grey background indicates edge-sharing octahedra/direct-exchange paths.

\begin{tabular}{cccccc}
\hline $\begin{array}{c}\text { Atom } \\
1\end{array}$ & $\begin{array}{c}\text { Atom } \\
2\end{array}$ & Distance $(\AA)$ & Angle $\left(^{\circ}\right)$ & Angle $\left(^{\circ}\right)$ & $\mathrm{J}$ \\
\hline $\mathrm{Cu} 1$ & $\mathrm{Cu} 3$ & $2.797(1)$ & $\mathrm{Cu} 1-\mathrm{O} 2-\mathrm{Cu} 3: 96.3(2)$ & $\mathrm{Cu} 1-\mathrm{O} 4-\mathrm{Cu} 3: 88.2(2)$ & $\mathrm{J}_{\Phi 2}$ \\
$\mathrm{Cu} 2$ & $\mathrm{Cr}$ & $2.950(1)$ & $\mathrm{Cu} 2-\mathrm{O} 1-\mathrm{Cr}: 97.0(2)$ & $\mathrm{Cu} 2-\mathrm{O} 5-\mathrm{Cr}: 94.1(2)$ & $\mathrm{J}^{\prime}$ \\
$\mathrm{Cu} 3$ & $\mathrm{Cr}$ & $2.977(1)$ & $\mathrm{Cu} 3-\mathrm{O} 2-\mathrm{Cr}: 101.3(2)$ & $\mathrm{Cu} 3-\mathrm{O} 3-\mathrm{Cr}: 94.7(1)$ & $\mathrm{J}_{2}$ \\
$\mathrm{Cr}$ & $\mathrm{Cr}$ & $3.054(2)$ & $\mathrm{Cr}-\mathrm{O} 1-\mathrm{Cr}: 99.3(2)$ & $\mathrm{Cr}-\mathrm{O} 2-\mathrm{Cr}: 101.5(2)$ & $\mathrm{J}_{\mathrm{a}}$ \\
\hline $\mathrm{Cu} 1$ & $\mathrm{Cr}$ & $3.261(1)$ & $\mathrm{Cu} 1-\mathrm{O} 2-\mathrm{Cr}: 118.2(2)$ & & $\mathrm{J}_{1}$ \\
$\mathrm{Cu} 2$ & $\mathrm{Cu} 3$ & $3.307(1)$ & $\mathrm{Cu} 2-\mathrm{O} 1-\mathrm{Cu} 3: 118.8(2)$ & & $\mathrm{J}_{\Phi 2}$ \\
$\mathrm{Cu} 2$ & $\mathrm{Cr}$ & $3.108(1)$ & $\mathrm{Cu} 2-\mathrm{O} 1-\mathrm{Cr}: 101.9(2)$ & & $\mathrm{J}_{4}$ \\
$\mathrm{Cu} 3$ & $\mathrm{Cr}$ & $3.169(1)$ & $\mathrm{Cu} 3-\mathrm{O} 2-\mathrm{Cr}: 108.6(2)$ & & $\mathrm{J}_{3}$ \\
$\mathrm{Cu} 3$ & $\mathrm{Cr}$ & $3.240(1)$ & $\mathrm{Cu} 3-\mathrm{O} 1-\mathrm{Cr}: 114.7(2)$ & & $\mathrm{J}_{2}$ \\
\hline
\end{tabular}

